varies greatly. With Nellhaus' case the neurological manifestations came on 20 days before the systemic ones, and with Chatterjee's case 24 days after. The interval between the onset of the sore throat and the detection of the hypoglassol palsy was 12 days in this case.

The pathological explanation for this neurological complication is presumably a local virus infection around the hypoglossal nerve nucleus. However, Bergin (1960), suggested that an 'allergic neurotaxitis' similar to that found in the encephalitis of measles and some other specific fevers might be responsible for some of the neurological manifestations of infectious mononucleosis.

\section{Acknowledgement}

I should like to thank Dr T. D. R. Hockaday for his advice and for his permission to publish the case.

\section{References}

BERGIN, J.D. (1960) Fatal encephalopathy in glandular fever. Journal of Neurology, Neurosurgery and Psychiatry, 23, 69. Cambier, J., Masson, M. \& Plamfossé, M.C. (1963) Diplegie faciale, complication evolutive d'une mononucleose infectieuse aiguie. La Presse Medicale, 71, 410.

Chatterjee, A. K. (1961) An unusual neurological complication of infectious mononucleosis. British Journal of Clinical Practice, 15, 595.

Davidson, R.J.L. \& SAlTER, R.H. (1964) Infectious mononucelosis presenting with facial diplegia. British Medical Journal, 1, 954.

EgAN, R.W. (1960) Facial diplegia in infectious mononucleosis in the absence of Landry-Guillain-Barre Syndrome. New England Journal of Medicine, 262, 1178.

Evans, J.G. (1963) Neurological complications of glandular fever. Ulster Medical Journal, 32, 31.

Gautier SMith, P.C. (1965) Neurological complications of glandular fever. Brain, 88, 323.

Nellhaus, G. (1966) Isolated oculomotor nerve palsy in infectious mononucleosis. Neurology, 15, 221.

RugG-GunN, M.A. (1954) Infectious mononucleosis. A review of the condition as seen in the Royal Navy. Proceedings of the Royal Society of Medicine, 47, 759.

Silverside, J.L. \& Richardson, J.C. (1950) Neurological complications of infectious mononucleosis. Canadian Medical Association Journal, 63, 138.

TAYlor, L. \& Parsons-Smith, G. (1969) Infectious mononucleosis, deafness and facial paralysis. Journal of Laryngology and Otology, 83, 613.

VAughaN, S.L., RegaN, J.S., \& TARPlaN, P.K. (1946) Infectious mononucleosis complicated by spontaneous rupture of the spleen and central nervous system involvement. Blood, 1, 334.

\title{
Successful resection of mycotic aneurysm of the superior mesenteric artery
}

\author{
C. R. Kumana \\ B.Sc., M.B., B.S., M.R.C.P.
}

R. J. E. FOLEY

M.B., B.S., F.R.C.S.

Whipps Cross Hospital, Leytonstone, London, E.11

\begin{abstract}
Summary
A patient with subacute bacterial endocarditis is presented in whom an intra-abdominal mycotic aneurysm was diagnosed prior to the development of cardiac signs. The patient was successfully treated for his endocarditis and the aneurysm which proved to be arising in a branch of the superior mesenteric artery was resected.
\end{abstract}

INTEREST in mycotic aneurysms was mainly academic until the advent of antibiotics, as until then the underlying disease was usually fatal. The superior mesenteric artery (with its branches) is rarely the site of an aneurysm, nonetheless, it constitutes a territory of predilection for mycotic aneurysms. The management of such aneurysms is complicated because the superior mesenteric artery is an end artery and the viability of the bowel it supplies must be maintained.

\section{Case report}

A 45-year-old man was admitted as an emergency with bizarre neurological symptoms.

He gave a 6 months' history of increasing malaise, aches and pains, anorexia and weight loss. This culminated in him giving up work 2 months prior to admission to this hospital, at which time he attended another hospital for his symptoms.

He presented at Whipps Cross Hospital with increasing drowsiness, associated with pain and stiffness of the left shoulder. He had been unable to swallow and would occasionally grimace and become incoherent. There was no past history of cardiac disease, but for the past 8 months he had been attending his dentist. 
Examination revealed an ill man with a pyrexia. The cardiovascular system and the abdomen were normal. He had some increase in tone in the left arm but this subsided overnight. The erythrocyte sedimentation rate was raised and blood culture grew Streptococcus viridans.

He was treated with parenteral penicillin and probenecid over the next 6 weeks. His general condition improved and blood cultures became negative. Towards the end of the course of treatment he was discharged home on therapy. However, he began experiencing abdominal pain. This was thought to be due to the probenecid and treatment was discontinued.

Abdominal pain persisted; he developed a pyrexia again and was re-admitted to hospital. Once more Streptococcus viridans was isolated from blood culture. His pain increased and he developed diarrhoea. Examination of the abdomen revealed a mass in the right lower quadrant, $6 \mathrm{~cm}$ in diameter, tender and expansile, and over it a systolic bruit could be heard. 2 days later a pansystolic cardiac murmur was heard at the apex for the first time.

An intra-abdominal mycotic aneurysm was diagnosed and as the mass was freely mobile the superior mesenteric was suspected to be the artery of origin. The mass increased in size over the next 6 days; locally the abdomen became more tender, although the bruit became softer and eventually inaudible. Aortogram under local anaesthetic by the Seldinger technique revealed no abnormality and immediately laparotomy was performed.

A largely clotted aneurysm, some $12 \mathrm{~cm}$ in diameter, was found in the mesentery originating from the ileal branch of the superior mesenteric artery. The proximal artery was ligated together with a number of smaller distal vessels. The aneurysm was excised. The vascularity of the small bowel remained unchanged during the procedure.

Postoperatively the patient did well. Antibiotics were discontinued after 3 months. He is now well

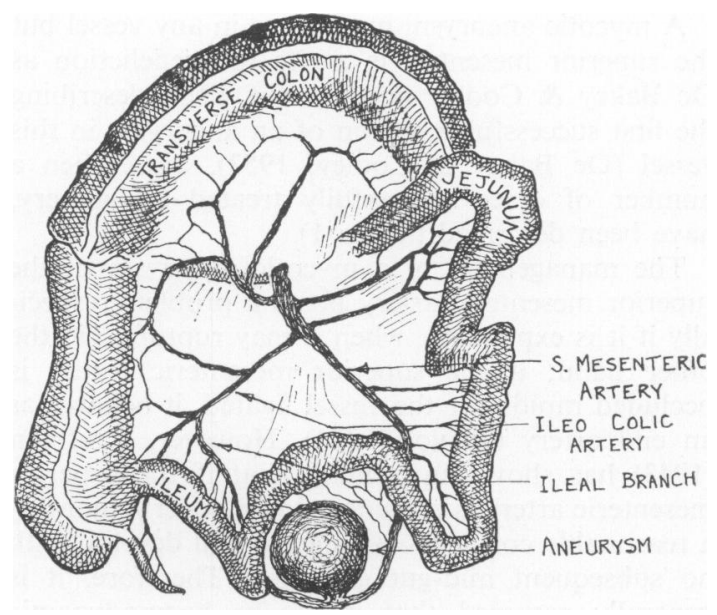

FIG. 1. Diagram showing site of aneurysm.

and symptom-free and has no signs of cardiac failure, although the pansystolic murmur at the apex remains.

\section{Discussion}

'Mycotic aneurysms of intravascular origin always occur in association with some underlying infectious process' (Stengel \& Wolferth, 1923). They found the infective process to be subacute bacterial endocarditis in $85 \%$ of cases. Until the introduction of antibiotics, the outcome was fatal and thus interest in mycotic aneurysms was mainly academic.

In the MRC series on subacute bacterial endocarditis (Cates \& Christie, 1957), haemorrhage from ruptured mycotic aneurysms accounted for $10 \%$ of the deaths. The incidence of this complication has not changed since the use of antibiotics (Rogers, 1956) and mycotic aneurysms may arise while the patient is on treatment as did the aneurysm in the case described here.

TABLE 1. Reported cases in which operation has been successful

\begin{tabular}{|c|c|c|c|c|}
\hline & Age & Sex & Aetiology & Operation \\
\hline De Bakey \& Cooley (1953) & 27 & $\mathbf{F}$ & SBE & Excision and ligation of SMA and SMV \\
\hline West (1954) & 23 & $\mathbf{F}$ & Not known & Aneurysmorrhaphy \\
\hline Katz \& Jacobson (1957) & 21 & $\mathbf{F}$ & SBE & Resection with four fifths of jejunum \\
\hline Horton (1959) & 31 & $\mathbf{M}$ & SBE & $\begin{array}{l}\text { Resection of aneurysm and ileocolic resection (after } \\
\text { rupture) }\end{array}$ \\
\hline Buchman \& Martin (1962) & 24 & $\mathbf{F}$ & SBE & $\begin{array}{l}\text { Resection of aneurysm with subsequent resection of } \\
\text { metre of small bowel }\end{array}$ \\
\hline Poblacion, McKenty \& Campbell (1964) & 24 & $\mathbf{F}$ & SBE & Ligation of SMA \\
\hline Frileux et al. (1964) & 61 & $\mathbf{M}$ & SBE & Obliterative endoaneurysmorrhaphy \\
\hline Alvarez, Parsonett \& Brief (1966) & 36 & $\mathbf{M}$ & SBE & Obliterative endoaneurysmorrhaphy \\
\hline Perlman \& Golinger (1967) & 14 & $\mathbf{M}$ & SBE & Ligature of SMA \\
\hline Present case (1970) & 45 & $\mathbf{M}$ & SBE & Resection of aneurysm \\
\hline
\end{tabular}

SBE, subacute bacterial endocarditis; SMA, superior mesenteric artery; SMV, superior mesenteric vein. 
A mycotic aneurysm may occur in any vessel but the superior mesentric is a site of predeliction as De Bakey \& Cooley pointed out when describing the first successful resection of an aneurysm in this vessel (De Bakey \& Cooley, 1953). Since then a number of cases successfully treated by surgery, have heen described (Table 1).

The management of a mycotic aneurysm of the superior mesenteric artery poses a problem, especially if it is expanding, when it may rupture. On the other hand, if the superior mesenteric artery is occluded rapidly or the vessel ligated, it behaves as an end artery (Mavor, 1961). However, Laufman (1943) has shown in animals that if the superior mesenteric artery is occluded slowly (over 4 months) a reasonable collateral circulation will develop with no subsequent mid-gut gangrene. Therefore, it is generally assumed that a similar haemodynamic result obtains with aneurysms of the superior mesenteric artery in man and that a reasonable collateral circulation will develop, given time.

As arterial reconstruction is rarely possible, surgery should be undertaken at a stage when the collateral circulation is sufficient to maintain the viability of the mid-gut. The superior mesenteric artery may then be safely ligated. The aneurysm should be resected to remove the infected focus.

\section{Acknowledgments}

Our thanks are due to Dr Eric Smith and Mr L. R. DeJode for their many helpful suggestions and for allowing us to report this case.

\section{References}

Alvares, J.F., Parsonnet, V. \& Brief, D.K. (1966) Mycotic aneurysm of the superior mesenteric artery. American Journal of Surgery, 3, 237.

Buchman, R.J. \& MARTIN, G.W. (1962) Management of mycotic aneurysm of the superior mesenteric artery. Annals of Surgery, 155, 620.

Cates, J.E. \& Christie, R.V. (1951) Subacute bacterial endocarditis. Quarterly Journal of Medicine, $20,93$.

De BAKey, M.E. \& CoOley, D.A. (1953) Successful resection of mycotic aneurysm of superior mesenteric artery. American Surgeon, 19, 202.

Frileux, C. Kapandi, I.A., Giuli \& Jullien, J.L. (1964) Rupture d'un anerrysme de l'artere mesenterique superieure. Endo-anerrysmorraphie obliterante. Guerison. Academie de Chirurgie, Paris, 90, 826.

HORTON, R.E. (1959) Ruptured mycotic aneurysm of superior mesenteric artery. British Journal of Surgery, 45, 541.

KATZ, B. \& JACOBSEN, L.F. (1957) Aneurysm of the superior mesenteric artery successfully treated. Surgery, 41, 613.

LAufman, H. (1943) Gradual occlusion of the mesenteric vessels. Surgery, 13, 406.

MavoR, G.E. (1961) Superior mesenteric artery occlusion. Proceedings of the Royal Society of Medicine, 54, 356.

Perlman, M. \& Golinger, D. (1967) Mycotic aneurysm of superior mesenteric artery successfully treated by ligation, with survival. British Journal of Surgery, 54, 735.

Poblacion, D., McKenty, J. \& Campbell, M. (1964) Mycotic aneurysm of the superior mesenteric artery complicating subacute bacterial endocarditis: successful resection. Canadian Medical Association Journal, 90, 744.

Rogers, L. (1957) Mycotic aneurysms and their treatment. Annals of the Royal College of Surgeons, 19, 257.

Stengel, A. \& Wolferth, C.C. (1923) Myctotic (bacterial) aneurysms of intravascular origin. Archives of Internal Medicine, 31, 527.

WEST, J.P. (1954) Aneurysm of the superior mesenteric artery successfully treated by restorative anaurysmorrhaphy. Annals of Surgery, 140, 882. 